\title{
Review of From Transmitted Deprivation to Social Exclusion: Policy, Poverty and Parenting
}

\author{
RANDY JOHNER \\ University of Regina, Canada
}

From Transmitted Deprivation to Social Exclusion: Policy, Poverty and Parenting. Written by John Welshman. Bristol, UK: Policy Press, 2012, ISBN 978-1-44730-586-6

This book is an intellectual history that traces the impact of Sir Keith Joseph's "cycle" speech, the direction taken by the subsequent research program at that time, and how the New Labour government of the $21^{\text {st }}$ century had arrived at their understanding of social exclusion and poverty, particularly in relation to that of families and children. The broad themes of this book comprise thirty five years of government and research community debates that focused on policy, poverty, and parenting in the UK.

This book is framed by two speeches: one on June 29, 1972 by Sir Keith Joseph, the then Conservative government Secretary of State for Social Services; and the other on September 5, 2006, by then New Labour government Prime Minister Tony Blair. Sir Keith Joseph's speech focused on the phenomenon of "transmitted deprivation" or a "cycle of deprivation" and why "deprivation and problems of maladjustment" persist. Prime Minister Blair's speech focused on tackling "social exclusion," as he called it, and a "hard core underclass." Although both of these speeches used different language, the reference to "problem families" or "intergenerational continuities," and "cycle of deprivation" has been consistent over time. What is particularly disquieting about Welshman's book is his ample evidence that affirms the consistent policy focus on so-called problem families who, for a multitude of reasons, are perceived as not "measuring" up to societal norms 
of acceptable behaviour.

As a social historian, John Welshman has astutely utilized archival documents (e.g. minutes of meetings and correspondence between ministers and civil servants), published documents and oral interviews with key players from Sir Keith Joseph's research program in the 1970s, to document the connections between the Conservative government and the research community's debates in understanding exclusion and intergenerational disadvantage. The unresolved issue of how to balance behavioural and structural causes of deprivation dating back to the 1970s continues to challenge $21^{\text {st }}$ century researchers and policy-makers. In addition, the perpetual focus on "problem families" remains unverified empirically. What ensues for the reader in this book is a fascinating intellectual history from the decade of the 1970s to 2007 of examining human behaviour and development through either a psychological lens or an economic lens but with little connection between these two lenses, and how scientific research, rigorous or otherwise, with its various personalities, lends itself to policy formation.

This book is divided into three sections: with the development of Sir Keith Joseph's cycle of deprivation; the direction of the governmentfunded Research Program that followed; and the many linkages between the Conservative government's research and analyses of the 1970s, and the New Labour government's approach to addressing poverty, exclusion and family maladjustment. The book methodically and skillfully presents an historical perspective of why the New Labour government adopted the 1970s Research Program thesis, "cycle of deprivation" in relation to "problem" families. Almost 35 years later, a largely behavioral deterministic approach in government policy to address social exclusion and poverty is still evident: problem families are the root cause of anti-social behaviours and thus should be the primary targets for intervention. Other approaches, such as a family ecological-systems approach that looks at the complex relationships between the individual, family and the environment, have only become relevant to the understanding of social exclusion in addition to the role of structural causes and agency in human behavior and development in recent years.

This is a well-written book, and Welshman establishes his expertise as a social historian in the area of current policy debates on policy, poverty and parenting. He provides the reader with ample historical evidence that the "cycle of deprivation" thesis is alive and well in contemporary society. This intellectual history of the "cycle of deprivation" encourages readers to critically re-think about current government policies that aim to promote inclusion and social justice as current policies may reveal little if any new insights from their predecessors. Most of the chapters detail Sir Keith Joseph's analysis of the "cycle of deprivation," and the Research Program that followed, with only a few chapters highlighting the research and political debates that framed the social exclusion agenda in the UK. However, numerous detailed analyses of the social exclusion agenda in the UK and elsewhere have been well-documented in the $21^{\text {st }}$ century. This book is suitable for (but not limited to) undergraduate and graduate level courses 
in social work, sociology, public policy, political science, family studies and human justice programs. Although it is definitely a methodical read it will be of particular interest to those readers who have some knowledge of the current social exclusion policy debates. 